\title{
Day time spawning of a Caribbean coral
}
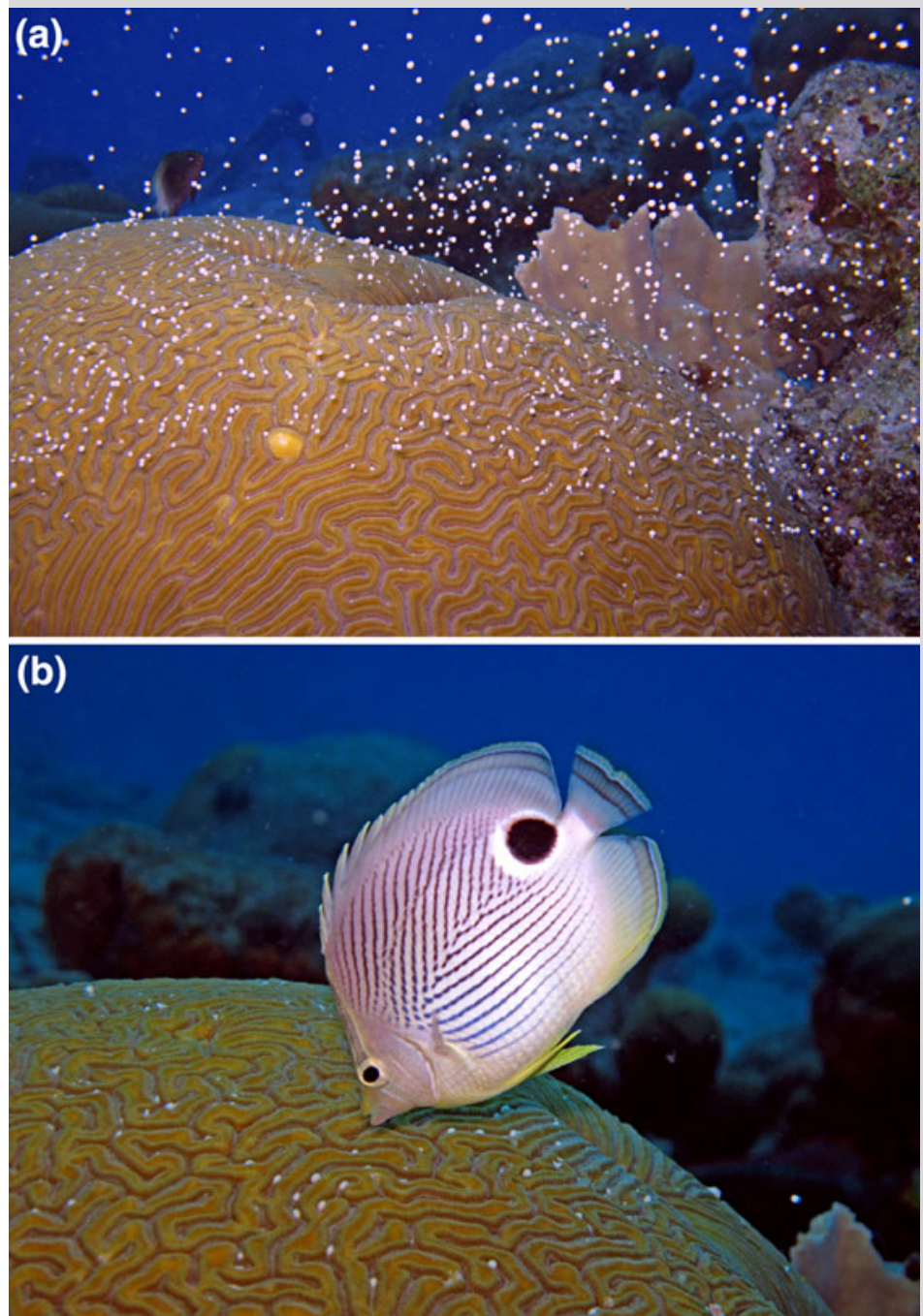

Fig. 1 a The release of gamete bundles by Diploria labyrinthiformis during the late afternoon on May 27, 2011. Note the blue background indicating that nightfall has not yet occurred. b Corallivores such as Chaetodon capistratus were observed feeding on the released gamete bundles
Diploria labyrinthiformis is a common Caribbean reef coral that releases gamete bundles between April and July depending on location within the Caribbean region (Weil and Vargas 2010). On 10 and 11 days after the full moon in May 2011 (i.e., May 27 th and 28th), the majority ( $>70 \%$; density of colonies $>10 \mathrm{~cm}: 0.15 \mathrm{~m}^{-2}$; M. J. A. Vermeij, personal observation) of $D$. labyrinthiformis colonies at a shallow reef (5-6 m) on Bari Reef, Bonaire $\left(12^{\circ} 10.021^{\prime} \mathrm{N}, 68^{\circ} 17.255^{\prime} \mathrm{W}\right)$ were observed releasing gamete bundles in the late afternoon (1800-1845 hours) just before nightfall at 1901 hours when the sun disappears below the horizon (Fig. 1). Spawning was also observed on June 27th, between 1815 and 1900 hours, likely by colonies that did not spawn in May. To our knowledge, this is the first time that colonies of a Caribbean coral species spawned simultaneously before nightfall. The species has been observed spawning at night 9-10 days after the full moon across the region, but reported spawning periods vary considerably (see references in Weil and Vargas 2010). Our observation indicates that the flexible reproductive timing of this species varies on even shorter temporal scales, i.e., between day and night. The adaptive mechanism behind such flexible spawning strategy is unclear at present, but favorable environmental conditions for subsequent settlement (e.g., presence of large amounts of open space due to low seasonal algal cover; Alvarado et al. 2004) and the maintenance of reproductive isolation from two co-occurring Diploria species that spawn in the fall (Weil and Vargas 2010) have been suggested as possible explanations. D. labyrinthiformis is a pioneer species on open space on shallow reefs on Bonaire and other islands in the region (Vermeij 2006) and locally dominates shallow water coral communities (M. J. A. Vermeij, personal observation). The unique reproductive flexibility observed in this species could help to increase its ecological success in times where most other Caribbean coral species decrease in abundance due to anthropogenic insults.

\section{References}

Alvarado EM, Garcia R, Acosta A (2004) Sexual reproduction of the reefbuilding coral Diploria labyrinthiformis (Scleractinia: Faviidae), in the Colombian Caribbean. Rev Biol Trop 52:859-868

Vermeij MJA (2006) Early life-history dynamics of Caribbean coral species on artificial substratum: the importance of competition, growth and variation in life-history strategy. Coral Reefs 25:59-71

Weil E, Vargas WL (2010) Comparative aspects of sexual reproduction in the Caribbean coral genus Diploria (Scleractinia: Faviidae). Mar Biol 157:413-426

E. Muller

Kaya Chopin 5, Antriol, Bonaire, Caribbean Netherlands

M. J. A. Vermeij $(\bowtie)$

CARMABI, Piscaderabaai z/n, Willemstad, Curaçao, Netherlands Antilles

e-mail: carmabilog@gmail.com

M. J. A. Vermeij

Aquatic Microbiology, Institute for Biodiversity and Ecosystem Dynamics, University of Amsterdam, Nieuwe Achtergracht 127,1018 WS Amsterdam, The Netherlands

Received: 3 June 2011/Accepted: 10 August 2011/Published online: 28 August 2011

Coral Reefs (2011) 30:1147

(C) Springer-Verlag 2011 